\title{
Key words for 2020: Pandemic, emergency, anomie
}

\author{
Liliana Lorettu \\ Psychiatric Clinic, Department of Medical, Surgical and Experimental Sciences, University of Sassari, Italy
}

\section{Dear Editor,}

In 2020, global society was disrupted by the COVID-19 pandemic, which has confronted everyone with an unusual, unknown situation, an unprecedented humanitarian emergency. The sudden outbreak has put health systems under enormous pressure and has caused major organisational problems, operational uncertainties and ethical conflicts. In particular, health workers had to deal with the emergency in both their personal and their working lives. While we wanted and had to treat our patients, we risked and feared getting infected too.

During the first wave of the pandemic, the sudden swell in patient numbers was such that it soon overwhelmed our intensive care resources. The situation was and still is an exceptional one, which has required a 'disaster medicine' response. ${ }^{1}$ When screening patients for ICU admission, we could no longer simply apply the criterion of appropriateness and proportionality of care. We also needed to weigh the principles of distributive justice and fair allocation of limited health resources. In Italy, SIAARTI (the Italian Society of Anaesthesiology, Analgesia, Resuscitation and Intensive Care) issued Clinical ethics recommendations for the allocation of intensive care treatment in exceptional, resource-limited circumstances. ${ }^{1}$ The recommendations are solidly grounded in ethical principles, to relieve clinicians from the burden of making subjective decisions, and introduce explicit resource allocation criteria. ${ }^{1}$ However, the resource shortage often resulted in dramatic discrimination by age group, concurrent medical conditions and patient characteristics. Thus, patients who were elderly, frail or with comorbidities were often denied access to the ICU. While some clinical guidance documents were issued, individual doctors were often left to grapple alone with their conscience when decid-

Correspondence: Liliana Lorettu, Psychiatric Clinic, Department of Medical, Surgical and Experimental Sciences, University of Sassari, Villaggio S.Camillo SS 200 Sassari 07100, Italy.

E-mail: 1lorettu@uniss.it

Key words: COVID-19, pandemic, emergency, anomie.

Conflict of interest: No one. This work was not supported by any grant.

Received for publication: 27 October 2020.

Accepted for publication: 6 November 2020 .

This work is licensed under a Creative Commons Attribution 4.0 License (by-nc 4.0).

C Copyright: the Author(s), 2021

Licensee PAGEPress, Italy

Emergency Care Journal 2021; 17:9436

doi:10.4081/ecj.2021.9436 ing, through an unusual triage, which patients would get ICU treatment and which would be left to die. ${ }^{2}$

The existing guidelines, organisational rules and operational protocols lost much of their validity as they were not designed to address the novel and continuously changing conditions.

The healthcare system, transformed by a business model driven by efficiency, productivity, cost reduction, procedural standardisation and control and strongly affected by budget cuts, has proved inadequate to deal with the emergency.

The pandemic diverted most available resources to the management of one disease (the COVID-19 infection) over other conditions (cardiovascular diseases, cancer); operational choices focused on the imperative of containing the spread of the infection, to the detriment of overall healthcare delivery.

The ethical principles of beneficence, non-maleficence and justice have been weakened or set aside outright.

Thus, the situation we are in today can be likened to that described in 1893 by Durkheim, who coined the word anomie. ${ }^{3}$ Durkheim used the concept of anomie to describe a situation of unease and malaise that occurs in a society when societal standards break down or become weakened and discordant. This concept includes both an objective dimension, referred to the social context, and a subjective dimension, which stems from the social context but concerns the individual, who experiences frustration due to the lack of points of reference and values. While for society the condition of anomie involves a strong risk of disintegration of the social fabric and deviance, ${ }^{4}$ for individuals it involves a deep state of alienation, due to their inability to choose the right course of action, as they do not know what others expect from them or what they can expect from others.

During the emergency, healthcare workers have often felt uncertainty, disorientation and loneliness both in their professional role and in their private lives.

And while the emergency of a few months ago has yet to settle in the 'container' of our emotions and we are still dazed by a sort of collective PTSD, we are on the verge of seeing it happen all over again, accompanied by the same uncertainty, loneliness and disorientation.

We are aware of the fluidity of emergency situations and thus we know that, once again, we might not have enough resources for everyone and it might again fall on us to decide who to treat and who to let die. We are also aware that after being hailed and celebrated as heroes, health professionals will be criticised, if not outright accused. And we will continue to debate in our conscience why the frailest patients were not always helped, and what we should do. Sometimes, our thoughts may be more personal: "Yesterday I was the one who made the choice. But what if, tomorrow, that frailer, needier patient is me? What will someone else choose for me?"

These moral dilemmas have heavily impacted the emotional resilience of clinical staff; we should not delay addressing the moral distress they experienced.

We are not sure we have learned the lesson from this tragedy; but those who do not learn from the past are doomed to repeat it. 
siaarti.it/SiteAssets/News/

\section{References}

1. SIAARTI. Raccomandazioni di etica clinica per l'ammissione a trattamenti intensivi e per la loro sospensione, in condizioni eccezionali di squilibrio tra necessità e risorse disponibili (Clinical ethics recommendations for the allocation of intensive care treatment in exceptional, resource-limited circumstances). Vers. 01, 06.03.2020. Available from: http://www.
2. Lorettu L. Aubut J, Ciliberti R. The new challenges for medical ethics (in press).

3. Durkheim E. The Division of Labour in Society. (Paris 1893). New York: The Free Press; 1997.

4. Merton Robert K. Social Theory and Social Structure. New York: the Free Press; 1968 